\title{
$\mathrm{Cr}_{3} \mathrm{C}_{2}$ を添加した $\mathrm{TiB}_{2}$ の焼結挙動
}

\author{
松下純一*, • 長島秀夫*,**・斎藤肇 $* * * *$ \\ *(株) STK 七ラミックス研究所, 455 名古屋市港区築三 1-11 \\ **東芝セラミックス中央研究所 (株), 257 秦野市兽屋 30 \\ *** 豊田工業大学工学部, 468 名古屋市天白区久方 2-12-2
}

\section{Sintering Behaviour of $\mathrm{TiB}_{2}$ with $\mathrm{Cr}_{3} \mathrm{C}_{2}$ Additive}

\author{
Junichi MATSUSHITA ${ }^{* \dagger}$, , Hideo NAGASHIMA ${ }^{* * *}$ and Hajime SAITO $* * * *$ \\ * STK Ceramics Laboratory Corp., 1-11, Tsukisan, Minato-ku, Nagoya-shi 455

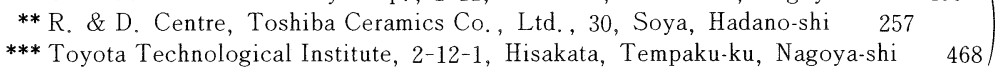

The effect of $\mathrm{Cr}_{3} \mathrm{C}_{2}$ additive was investigated on the sintering process of $\mathrm{TiB}_{2}$. The 5-7.5 wt\% of $\mathrm{Cr}_{3} \mathrm{C}_{2}$ well functioned to improve the relative density, the bending strength and Vickers hardness. According to the X-ray diffraction data, TiC and $\mathrm{CrB}$ were formed at the grain boundaries of $\mathrm{TiB}_{2}$. Also, the solid solution between $\mathrm{Ti}_{2}$ and $\mathrm{Cr}_{3} \mathrm{C}_{2}$ was recognized. The $S E M$ observation supported that a liquid phase was significantly concerened in the sintering of Ti $B_{2}$. The sintering behaviour of $\mathrm{TiB}_{2}$ was discussed on the microstructural and compositional viewpoints.

[Received September 21, 1989; Accepted December 11, 1989]

Key-words : $\mathrm{TiB}_{2}, \mathrm{Cr}_{3} \mathrm{C}_{2}$, Pressureless sintering, Densification, Microstructure, Solid solution

\section{1. 緒 言}

$\mathrm{TiB}_{2}$ は高融点，高硬度，良導電性など優れた特性を 持ち, 切削工具材, 而熱材あるいは耐摩耗部材などとし て利用できるものと考えられている.

近年, $\mathrm{TiB}_{2}$ の焼結に関する研究がいくつかなされて おり，渡辺ら”は， $\mathrm{TiB}_{2} に \mathrm{CoB}$ あるいは $\mathrm{TaB}_{2}$ を添加 して，ホットプレス焼結を行うことにより，緻密で高強 度の焼結体が得られると報告している。また，西山ら ${ }^{21}$ は， $\mathrm{TiB}_{2}$ 焼結体の緻密化に $\mathrm{Ni}-\mathrm{Zr}$ 合金が有効であるこ とを示した.

著者らは， $\mathrm{TiB}_{2}$ の常圧焼結の可能性を探ることを目 的に研究を行い, 先に, $\mathrm{TiB}_{2}$ に $\mathrm{Cr}_{3} \mathrm{C}_{2}$ を添加すること が $\mathrm{TiB}_{2}$ の緻密化に有効であることを報告した ${ }^{3\}}$.しか しながら， $\mathrm{TiB}_{2}-\mathrm{Cr}_{3} \mathrm{C}_{2}$ 系セラミックスにおける， $\mathrm{Cr}_{3} \mathrm{C}_{2}$ の役割は明らかでなかったため，本報では， $\mathrm{TiB}_{2}$ の焼 結に対する $\mathrm{Cr}_{3} \mathrm{C}_{2}$ 添加の影響について更に詳しく調へ， 緻密化の機構について検討したのでその結果を報告す る.

†現在：東芝セラミックス (株), 448 刈谷市小垣江町南藤 1 Now with Toshiba Ceramics Co., Ltd., 1, Minamifuji, Ogakie-cho, Kariya-shi 448

\section{2. 実験方法}

出発原料として用いた Cerac 社製 $\mathrm{TiB}_{2}$ 粉末及び添川 理化学製の $\mathrm{Cr}_{3} \mathrm{C}_{2}$ 粉末の平均粒径及び化学分析值を表 1 に示す。平均粒径及び化学分析值はメ一カ一側によっ て示された分析值である．使用した両粉末の粒度を自動 粒子解析装置 (Leeds \& Northrup 社, マイクロトラッ ク粒度分析計）によって測定した結果を図 1 に示す. $\mathrm{TiB}_{2}$ 粉末は粒子中心径が約 $5 \mu \mathrm{m}$ の粉末であり, $\mathrm{Cr}_{3} \mathrm{C}_{2}$ 粉末は粒子中心径が約 $18 \mu \mathrm{m}$ の粉末であった。両粉末 の酸素量及び炭素量をLeco 社製の酸素，炭素分析装置 を用いて測定した結果を表 2 に示す.

これらの粉末を所定の割合に配合して，プラスチック

Table 1. Average particle size and chemical composition of raw materials.

\begin{tabular}{ccc}
\hline Material & $\begin{array}{l}\text { Average particle } \\
\text { size }(\mu \mathrm{m})\end{array}$ & Composition $($ wto $)$ \\
\hline $\mathrm{TiB}_{2}$ & 2.65 & $\mathrm{~B}: 30.50, \mathrm{Al}: 0.1, \mathrm{Fe}: 0.2$ \\
& $\mathrm{Mg}: 0.30, \mathrm{Cr}: 0.001, \mathrm{~S} 1: 0.3$ \\
& $\mathrm{Ca}: 0.01$ \\
$\mathrm{Cr}_{3} \mathrm{C}_{2}$ & 7.5 & $\mathrm{Cr}: 86.2, \mathrm{Fe}: 0.07, \mathrm{~S} 1: 0.008$ \\
& & Total carbon: 13.1 \\
& & Free carbon: 0.2 \\
\end{tabular}




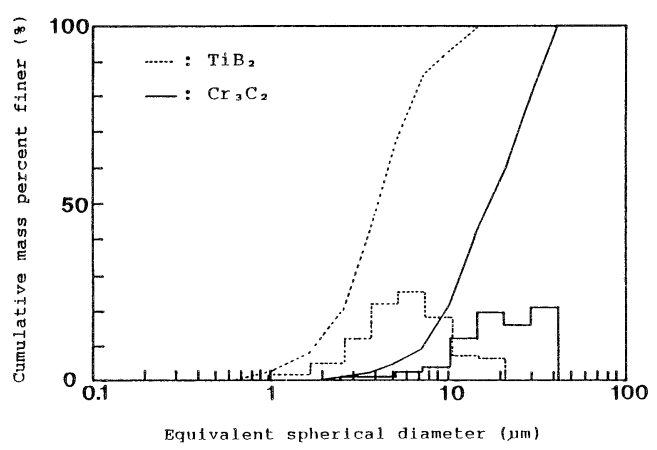

Fig. 1. Particle size distribution of raw materials.

Table 2. Total oxygen and carbon contents of raw materials.

\begin{tabular}{lcc}
\hline Material & Total oxygen(wtz) & Total carbon(wtz) \\
\hline $\mathrm{TiB}_{2}$ & 0.9 & 0.6 \\
$\mathrm{Cr}_{3} \mathrm{C}_{2}$ & 0.2 & - \\
\hline
\end{tabular}

容器及びナイロン製ボールを用いて, エチルアルコール 中で 24 時間，湿式による混合を行った。この原料混合 物を乾燥させた後, $30 \mathrm{MPa}$ でプレス成形し, 更に 300 $\mathrm{MPa}$ で CIP 成形を行うことにより所定の成形体を作製 した。ついで, 成形体をカーボン容器に充填した後, こ れを抵抗加熱式 (カーボン発熱体) 電気炉において, $1900^{\circ} \mathrm{C}$, アルゴンガス雾囲気下, 1 時間の焼結反応を行っ た。昇温速度は， $15^{\circ} \mathrm{C} / \mathrm{min}$ に設定したが焼結後は，そ のままアルゴンガス雾囲気中で炉内徐冷した。

焼結体の密度，曲げ強度及びビッカ一ス硬さの測定方 法については前報 ${ }^{31}$ と同様とした。

得られた焼結体の結晶相は，試料を粉砕し，粉末 $\mathrm{X}$ 線 回折法により同定した。X 線回折は日本電子製の粉末 $\mathrm{X}$ 線回折装置（型式 $11 \mathrm{RA}$ ) を用いて, CuK $\alpha$ 線で測定 した.X 線分析は日本電子製 JCMA 733 を用いて調べ た。組織は, 光学顕微鏡（ニコン製，モデル 104）及び 走査型電子顕微鏡（SEM：日立製作所製，S 530）にて

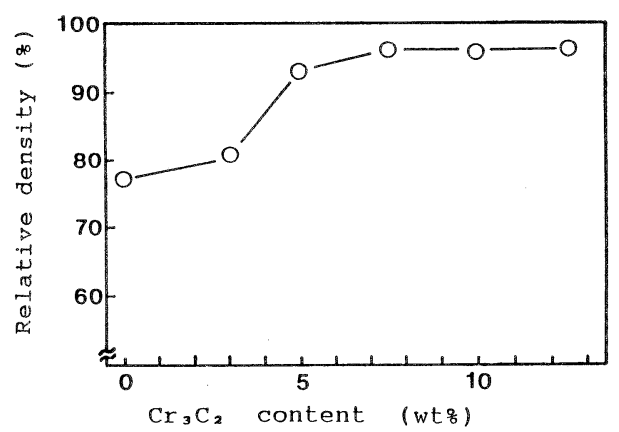

Fig. 2. Relative density as a function of $\mathrm{Cr}_{3} \mathrm{C}_{2}$ content.

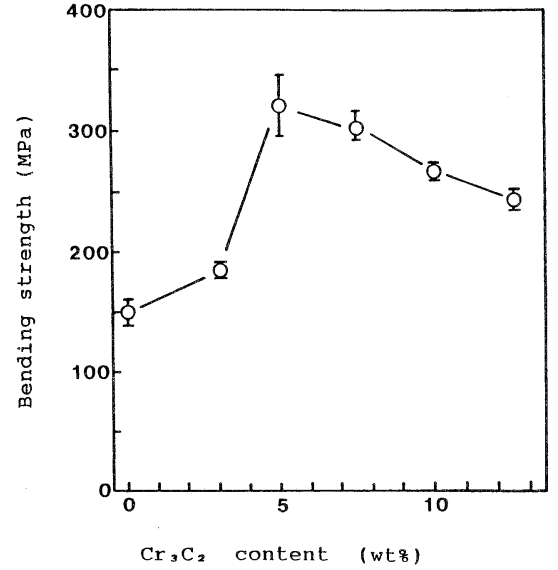

Fig. 3. Bending strength as a function of $\mathrm{Cr}_{3} \mathrm{C}_{2}$ content.

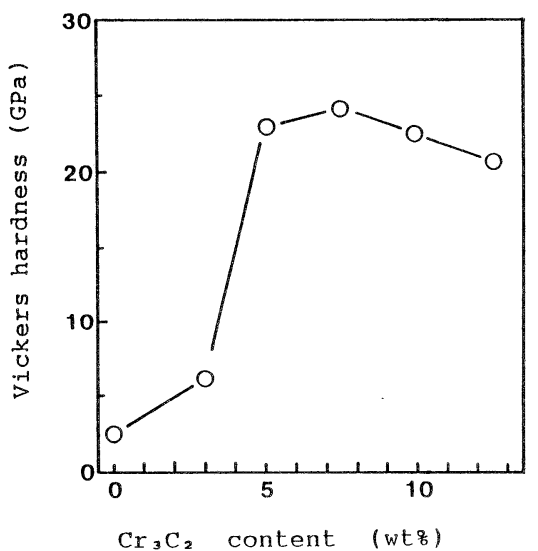

Fig. 4. Vickers hardness as a function of $\mathrm{Cr}_{3} \mathrm{C}_{2}$ content.

観察した。

\section{3. 実験結果}

\section{$3.1 \mathrm{Cr}_{3} \mathrm{C}_{2}$ 添加による焼結体密度, 曲げ強度及びビッ} カース硬さへの影響

$\mathrm{TiB}_{2}$ に $\mathrm{Cr}_{3} \mathrm{C}_{2}$ を添加して $1900^{\circ} \mathrm{C} て ゙ 1$ 時間, 焼結を 行い，得られた焼結体について $\mathrm{Cr}_{3} \mathrm{C}_{2}$ 添加量之相対密 度，曲げ強度及びビッカース硬さとの関係を調べた! それらの結果を図2 2 図4 に示す。 $\mathrm{Cr}_{3} \mathrm{C}_{2}$ 添加量と相対 密度との関係から， $\mathrm{TiB}_{2}$ 単味の焼結体に比べて $\mathrm{Cr}_{3} \mathrm{C}_{2}$ を $5 \mathrm{wt} \%$ 以上添加した組成では，相対密度が $95 \%$ 以上 になり， $\mathrm{Cr}_{3} \mathrm{C}_{2}$ の添加により高密度の焼結体が得られる ことが分かった. $\mathrm{Cr}_{3} \mathrm{C}_{2}$ 添加量と曲げ強度及びビッカー 不更さとの関係については, $\mathrm{Cr}_{3} \mathrm{C}_{2}$ の添加量が $5 \sim 7.5$ wt \% で曲げ強度及びビッカース硬さに最大值が現れ， $\mathrm{TiB}_{2}$ 単味焼結体の曲げ強度及びビッカース硬さに比べ て著しく強度，硬度が向上した。しかしながら，それ以 上に $\mathrm{Cr}_{3} \mathrm{C}_{2}$ を添加した組成については，緻密化が進行 


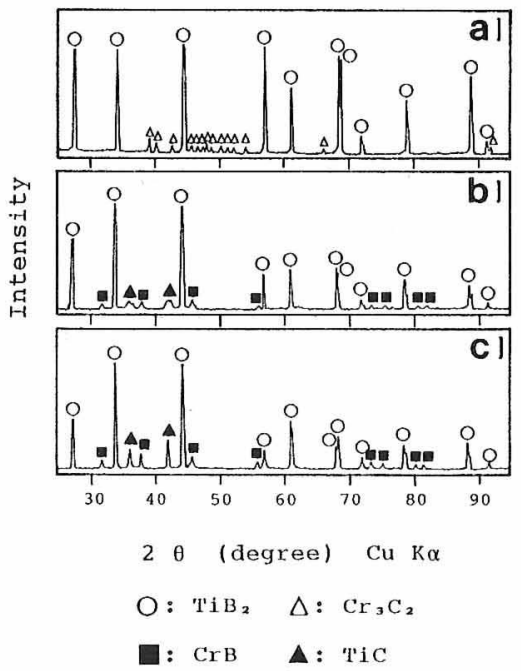

Fig. 5. X-ray diffraction patterns for (a) $\mathrm{TiB}_{2}-$ $7.5 \mathrm{wt} \% \quad \mathrm{Cr}_{3} \mathrm{C}_{2}$ material sintered at $1100^{\circ} \mathrm{C}$, (b) $\mathrm{TiB}_{2}-7.5 \mathrm{wt} \% \mathrm{Cr}_{3} \mathrm{C}_{2}$ material sintered at $1300^{\circ} \mathrm{C}$ and (c) $\mathrm{TiB}_{2}-7.5 \mathrm{wt} \% \quad \mathrm{Cr}_{3} \mathrm{C}_{2}$ material sintered at $1900^{\circ} \mathrm{C}$.

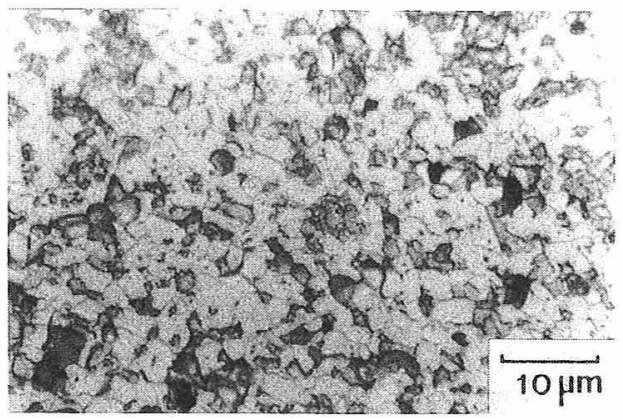

Fig.6. Microphotograph of polished surface of $\mathrm{TiB}_{2}-7.5 \mathrm{wt} \% \mathrm{Cr}_{3} \mathrm{C}_{2}$ composite sintered at $1900^{\circ} \mathrm{C}$ after etching chemically by $\mathrm{HNO}_{3}$ liquids.

するにもかかわらず，曲げ強度及びビッカース硬さは低 下する傾向を示した.

\section{2 焼結時の相変化}

$\mathrm{TiB}_{2}$ に $7.5 \mathrm{wt} \%$ の $\mathrm{Cr}_{3} \mathrm{C}_{2}$ を添加し, $1100^{\circ} \mathrm{C}$, $1300^{\circ} \mathrm{C}$ 及び $1900^{\circ} \mathrm{C}$ の各温度について处理した後, 得 られた試料の粉末 X 線回折図形を図 5 に示す. $1100^{\circ} \mathrm{C}$ で焼成した試料では，出発物質の $\mathrm{TiB}_{2}$ 之 $\mathrm{Cr}_{3} \mathrm{C}_{2}$ のピ一 クのみが検出された。 $1300^{\circ} \mathrm{C}$ 以上で焼成した試料では $\mathrm{Cr}_{3} \mathrm{C}_{2}$ のピークが消失し, ブロードではあるが $\mathrm{CrB}$ と

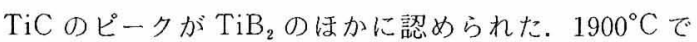
焼成した試料について, $\mathrm{TiB}_{2}$ とシャープな $\mathrm{CrB}$ と $\mathrm{TiC}$ のピークが検出された。

これらのことから， $\mathrm{TiB}_{2}$ マトリックス中に生成する $\mathrm{CrB}$ と $\mathrm{TiC}$ が，液相となり $\mathrm{TiB}_{2}$ の粒子間拡散を著し く促進することにより焼結が進行，緻密化したものと考 えられる.このことの詳細については後述する.
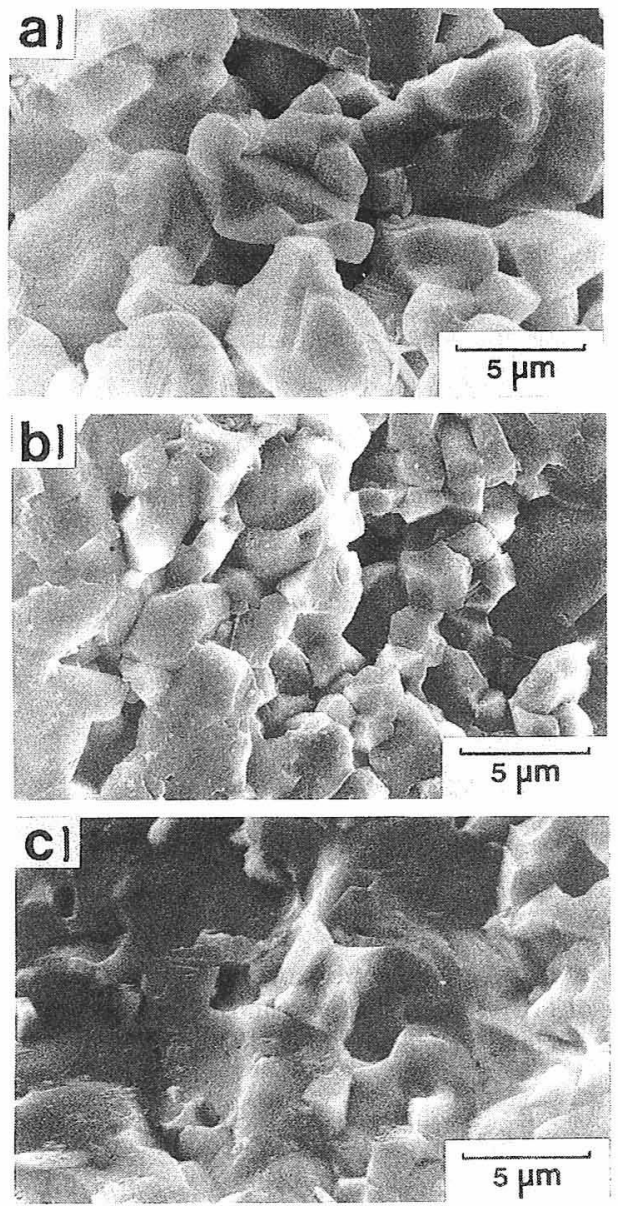

Fig. 7. Scanning electron micrographs of fracture surface of (a) $\mathrm{TiB}_{2} 100 \mathrm{wt} \%$, (b) $\mathrm{TiB}_{2}-5 \mathrm{wt} \% \mathrm{Cr}_{3} \mathrm{C}_{2}$ and (c) $\mathrm{TiB}_{2}-10 \mathrm{wt} \% \mathrm{Cr}_{3} \mathrm{C}_{2}$ composites sintered at $1900^{\circ} \mathrm{C}$.

\section{4. 考察}

\section{1 機械的性質と微構造}

$\mathrm{TiB}_{2} に 5 \mathrm{wt} \%$ の $\mathrm{Cr}_{3} \mathrm{C}_{2}$ を添加して $1900^{\circ} \mathrm{C}$ で得られ た焼結体について, $\mathrm{HNO}_{3}$ でエッチング処理後の表面の 光学顕微鏡写真を図 6 に示す. 図から明らかなように, 2 3 $\mu \mathrm{m}$ の大きさからなる $\mathrm{TiB}_{2}$ 粒子は粒成長が顕著で なく, 粒子外形は全体に丸みをおび，しかも粒がよくそ ろっている.

図 7 に $1900^{\circ} \mathrm{C}$ で焼結を行った $\mathrm{TiB}_{2}$ 及び, $\mathrm{Cr}_{3} \mathrm{C}_{2}$ を それぞれ 5, $10 \mathrm{wt} \%$ 添加した $\mathrm{TiB}_{2}$ 焼結体の破断面の $\mathrm{SEM}$ 写真を示す。 $\mathrm{TiB}_{2}$ 単味からなる焼結体の破断面 は粒界破壊が支配的であるのに対して, $\mathrm{Cr}_{3} \mathrm{C}_{2}$ を 10 $\mathrm{wt} \%$ 添加した焼結体のそれは, 大部分が粒内破壊を起 こしていることがわかる.

図 8 に $5 \mathrm{wt} \%$ の $\mathrm{Cr}_{3} \mathrm{C}_{2}$ を添加して得られた焼結体の 表面を $\mathrm{HNO}_{3}$ でエッチング処理した組織の SEM 像を 示す，図から明らかなように， $\mathrm{TiB}_{2}$ 粒子は連続した粒 


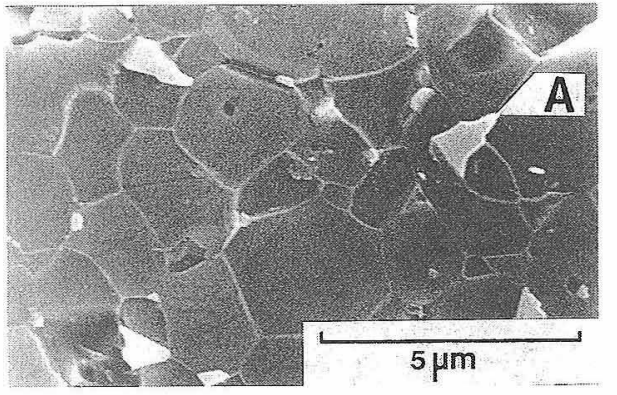

Fig. 8. Scanning electron micrograph of polished surface of $\mathrm{TiB}_{2}-5 \mathrm{wt} \% \mathrm{Cr}_{3} \mathrm{C}_{2}$ composite sintered at $1900^{\circ} \mathrm{C}$ after etching chemically by $\mathrm{HNO}_{3}$ liquids.

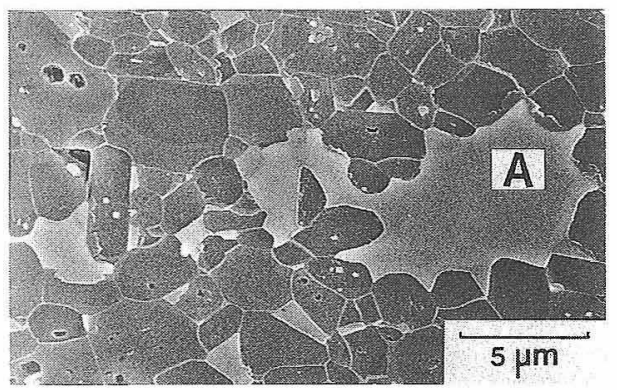

Fig. 9. Scanning electron micrograph of polished surface of $\mathrm{TiB}_{2}-10 \mathrm{wt} \% \mathrm{Cr}_{3} \mathrm{C}_{2}$ composite sintered at $1900^{\circ} \mathrm{C}$ after etching chemically by $\mathrm{HNO}_{3}$ liquids.

界相により取り囲まれて，あまり粒成長していない。更 に， $\mathrm{A}$ 部のような，析出相とみなされる相が $\mathrm{TiB}_{2}$ 粒子 の近傍に生成した.これは $\mathrm{Cr}_{3} \mathrm{C}_{2}$ の添加量が増加する のに伴って増加し， $\mathrm{Cr}_{3} \mathrm{C}_{2}$ 添加量が $10 \mathrm{wt} \%$ の焼結体で， かなりの量の析出相が観察され，著しく成長したものも 楒められた。(図 9, A 部)このことから， $\mathrm{TiB}_{2}$ 粒界に は液相が存在したもの上推測された。

図2４に示したように $5 \mathrm{wt} \%$ 以上の $\mathrm{Cr}_{3} \mathrm{C}_{2}$ を添加す ると緻密な焼結体が得られるにもかかわらず，7.5 wt\% 以上の $\mathrm{Cr}_{3} \mathrm{C}_{2}$ を添加した組成の試料では, 曲げ強度及 びビッカ一ス硬さが低下する傾向がみられた。

このことは, $\mathrm{Cr}_{3} \mathrm{C}_{2}$ の添加量の増加に伴って $\mathrm{TiB}_{2}$ 粒 子の周囲に生成する析出相が著しく増加する結果, 曲げ 強度及びビッカース硬さの低下をもたらしたものと考え られる。

図 10 に $\mathrm{TiB}_{2}$ に $7.5 \mathrm{wt} \%$ の $\mathrm{Cr}_{3} \mathrm{C}_{2}$ を添加して得られ た焼結体のX線面分析結果を示す. 図 $10(\mathrm{a})$ 一 (c) 上り, この析出相は Cr を多く含む相であることが分かる。

図 11 K $\mathrm{TiB}_{2}$ の (201) X 線回折ピークを示すが，出 発粉末のそれに比べて, $\mathrm{Cr}_{3} \mathrm{C}_{2}$ を添加した $\mathrm{TiB}_{2}$ 焼結体 のそれは高角度側へ移動していることが分かる。これは， 試料中の $\mathrm{TiB}_{2}$ 結晶の単位格子が, $\mathrm{Cr}$ の固溶により収 縮することによって回折線が高角度側に移動したものと
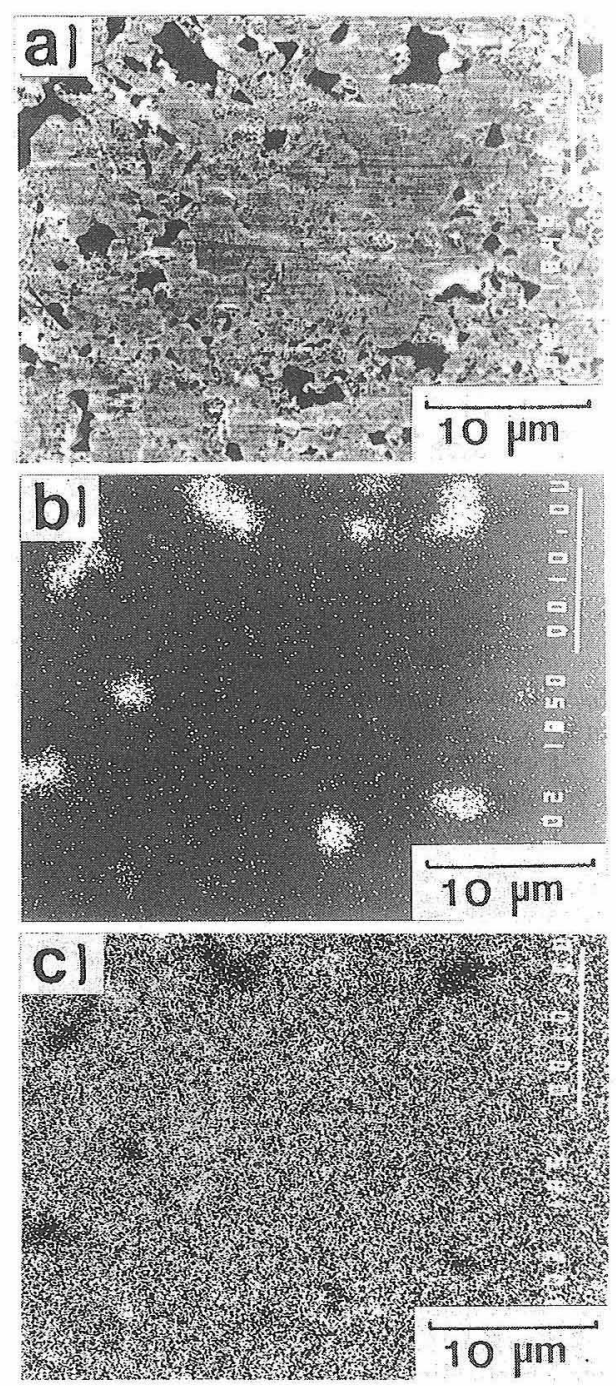

Fig. 10. Scanning electron micrograph and X-ray image micrographs of $\mathrm{TiB}_{2}-7.5$ wt $\% \quad \mathrm{Cr}_{3} \mathrm{C}_{2}$ composite sintered at $1900^{\circ} \mathrm{C}$. (a) Microstructure, (b) The distribution of $\mathrm{Cr}$ element and (c) The distribution of $\mathrm{Ti}$ element.

考えられる。

これらのことから, $\mathrm{TiB}_{2}$ は固溶体を生じていると推 察できる.

\section{2 焼結挙動と緻密化}

4.1 節で述べたように, $\mathrm{Cr}_{3} \mathrm{C}_{2}$ を添加した $\mathrm{TiB}_{2}$ の緻 密化は液相の生成に起因しているもの上考えられる。こ の液相が，マトリックスの $\mathrm{TiB}_{2}$ 粒子の周囲を被うこと により、 $\mathrm{Ti}$ と $\mathrm{B}$ 原子が溶解して $\mathrm{TiB}_{2}$ の拡散を促進さ せたものと考えられる.そして，この液相を通して粒界 相には $\mathrm{CrB}$ と $\mathrm{TiC}$ の混合相が形成され，一部 $\mathrm{TiB}_{2}$ と の固溶体が形成されるものと考えられる.

これらのことから， $\mathrm{TiB}_{2}$ に $\mathrm{Cr}_{3} \mathrm{C}_{2}$ を添加することに 


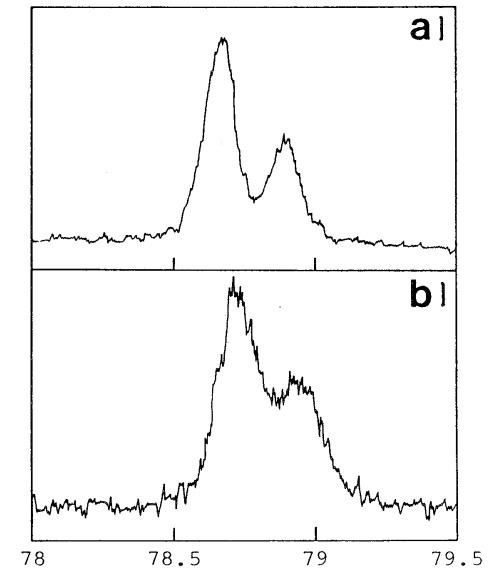

$\mathrm{Cu}-\mathrm{K} \alpha \quad 2 \theta \quad$ (deg.)

Fig. 11. X-ray diffraction patterns of $\mathrm{TiB}_{2}(201)$. (a) $\mathrm{TiB}_{2}-7.5 \mathrm{wt} \% \quad \mathrm{Cr}_{3} \mathrm{C}_{2}$ raw material and (b) $\mathrm{TiB}_{2}-$ 7.5 wt $\% \mathrm{Cr}_{3} \mathrm{C}_{2}$ composite sintered at $1900^{\circ} \mathrm{C}$.

より緻密で高強度, 高硬度の焼結体が得られるものと推 察される。

\section{5. 結 言}

$\mathrm{Cr}_{3} \mathrm{C}_{2}$ を添加した $\mathrm{TiB}_{2}$ 焼結体の焼結挙動について検 討した結果，次のような結論を得た。

(1) $\mathrm{TiB}_{2}$ に $\mathrm{Cr}_{3} \mathrm{C}_{2}$ を添加して焼結すると, 反応生 成相として $\mathrm{CrB}$ と $\mathrm{TiC}$ が生成して, 液相焼結によって 緻密化することが分かった。

（2） 添加した $\mathrm{Cr}_{3} \mathrm{C}_{2}$ は，一部 $\mathrm{TiB}_{2}$ と反応して固溶 体を形成すると考えられる。

（3）焼結体中の粒界相及び析出相は $\mathrm{CrB}$ と $\mathrm{TiC}$ で あることが分かった。

（4）析出相の増加及び成長が，曲げ強度及びビッ カース硬さの低下を引き起こすことが分かった。

\section{文献}

1) T. Watanabe and S. Kouno, Am. Ceram. Soc. Bull., 61, 970-73 (1982).

2）西山勝廣，梅川荘吉，粉体粉末冶金協会春季大会講演概 要集, 74-75 (1985).

3）松下純一, 長島秀夫, 斎藤 肇, セラミックス論文誌, 98, 355-59 (1990). 